\title{
Chapter 6 \\ Ex Vivo Enzymatic Conversion of Non-food Cellulose Biomass to Starch
}

\section{Chun You and Y.H. Percival Zhang}

\begin{abstract}
To meet the world's rising future food/feed needs, outputs of modern agriculture must grow substantially while minimizing agriculture's environmental footprint and conserving biodiversity. In this chapter, we propose an ex vivo synthetic enzymatic pathway to enable the transformation of non-food cellulose to amylose, a high-value linear starch, meanwhile glucose released by enzymatic hydrolysis of cellulose is used to produce ethanol and/or single-cell protein by yeast fermentation in the same vessel. The strategy of simultaneous enzymatic biotransformation and microbial fermentation is the basis of new biomass biorefineries that would address the food, fuels, and environment trilemma by coproducing food/feed, biomaterials, and biofuels from the most abundant renewable bioresource - non-food lignocellulosic biomass. Toward this development, new directions pertaining to pretreatment of lignocellulosic biomass and advanced enzyme engineering are discussed to increase the efficiency of saccharification.
\end{abstract}

Keywords Bioeconomy • New biorefinery • Food and feed · Invitro synthetic biology $\cdot$ Synthetic amylose $\cdot$ Food-energy-water nexus

\subsection{Introduction}

The continuing growth of population and food consumption per capita means that the global demand for food could increase by $70 \%$ by 2050 [1, 2]. In the developed countries, starch provides at least $35 \%$ of man's daily intake, whereas, this value may

C. You $(\bowtie) \cdot$ Y.H.P. Zhang $(\square)$

Tianjin Institute of Industrial Biotechnology, Chinese Academy of Sciences, 32 West 7th Avenue, Tianjin Airport Economic Area, Tianjin 300308, China e-mail: you_c@tib.cas.cn

Y.H.P. Zhang

e-mail: ypzhang@vt.edu

C. You - Y.H.P. Zhang

Biological Systems Engineering Department, Virginia Tech, 304 Seitz Hall,

Blacksburg, VA 24061, USA 
go to $80 \%$ in most developing countries, especially in Africa and the far East. Increase in the supply of starch food to fight against hunger is becoming a global challenge. However, approximately $30 \%$ of the world's arable land and $70 \%$ of the world's fresh water withdrawals are being used for the production of food and feed to support seven billion people [3]. It is difficult to greatly increase arable land to agricultural use due to its other use and increase freshwater withdrawals. Some solutions were proposed to solve potential food crisis, like increasing agricultural resource efficiency, closing yield gaps on underperforming lands, reducing food waste, and developing genetically modified (GM) crops. However, long-term impacts of GM cereals as staple food on human health are not clear and their wide acceptance is in heated debates, especially in China and Europe [4, 5]. On the other hand, modern agriculture is also environmentally destructive, because some forests have been cut down and wetlands have been drained, more use of fertilizers and pesticides have caused serious environmental problems, such as changes in ecosystems, nonpoint water runoff pollution, climate changes, and decreased biodiversity [6].

Cellulose and starch are both anhydroglucose polymers, which are major products derived to plant photosynthesis. Cellulose is the supporting material of plant cell walls and the most abundant renewable bioresource on earth. It is a linear glucan linked by $\beta-1,4$-glucosidic bonds. Annual production of cellulose is estimated to be 100 billion tonnes [7]. It can be derived from a variety of sources, such as wood, agriculture residues, perennial plants, and so on. Humans, unlike herbivores, cannot utilize cellulose-containing biomass as a food source. Starch is the most important diet component for humans because it provides more than $50 \%$ calories of healthy diets. It is a polysaccharide consisting of a large number of anhydroglucose units joined together primarily by $\alpha$-1,4-glucosidic bonds and $\alpha-1,6$-glucosidic bonds. Three major crops for producing starch-rich seeds are maize, rice, and wheat. However, dedicated cereal crops produce approximately 2.8 billion tonnes of starch-rich cereals annually, much less than annual cellulose production (Fig. 6.1). Due to the same building block (i.e., anhydroglucose) of cellulose and starch, the cost-effective transformation of non-food cellulose to edible starch could drastically enhance food security, while revolutionizing agriculture from cultivating annual seed-harvesting plants to perennial cellulose-rich plants, maintaining biodiversity, minimizing agriculture's environmental footprint, decrease inputs of fertilizers and herbicide, lowering energy consumption of farming machinery, and conserving fresh water [8]. This transformation cannot be done efficiently by microorganisms because of inherent side-reactions of microorganisms and cellular membrane that can prevent large molecular weight polymeric compounds such as cellulose and starch to go through. However, ex vivo synthetic enzymatic biosystems can implement this seemingly mission impossible task by assembling cascade enzymes outside cell membranes. Such ex vivo systems have many appealing advantages, like high product yield, faster reaction rate, great engineering flexibility, and high tolerance to toxic compounds [9-15]. 


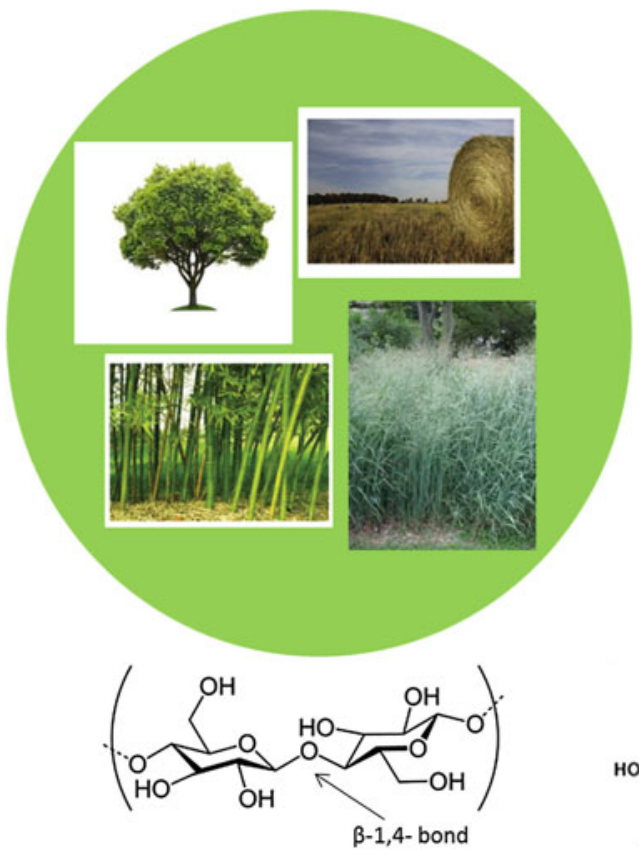

Starch food (maize, rice, wheat)

2.8 billion tons

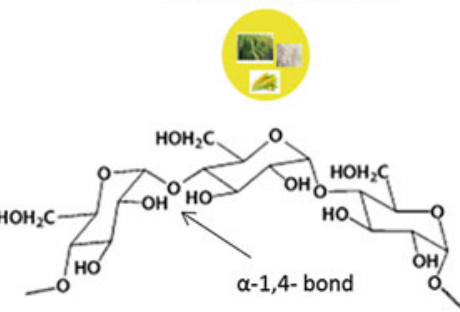

Fig. 6.1 The annual production of cellulose and starch on earth

Here we demonstrate simultaneous (ex vivo) enzymatic transformation and microbial fermentation that can transform cellulosic materials to starch, ethanol, and single-cell protein in one pot.

\subsection{Transform Cellulose to Starch}

An ex vivo enzymatic pathway has been designed to transform cellulose to synthetic amylose in an aqueous solution (Fig. 6.2a) [16]. This enzyme cocktail has two modules: (1) partial hydrolysis of cellulose to cellobiose by an optimized mixture of cellobiohydrolase (CBH) and endoglucanase (Endo), and (2) amylose synthesis by utilizing cellobiose phosphorylase (CBP) and potato alpha-glucan phosphorylase (PGP). In this system, CBP converts cellobiose to glucose 1-phosphate (G1P) and glucose in the presence of phosphate ions; PGP adds one glucose unit from G1P at the nonreducing end of amylose, and phosphate is recycled to maintain nearly constant $\mathrm{pH}$ and phosphate levels (Fig. 6.2a). To eliminate glucose inhibition, the ethanol-producing yeast Saccharomyces cerevisiae is added to the vessel because the yeast cannot utilize cellobiose and G1P [17, 18]. 
(a)

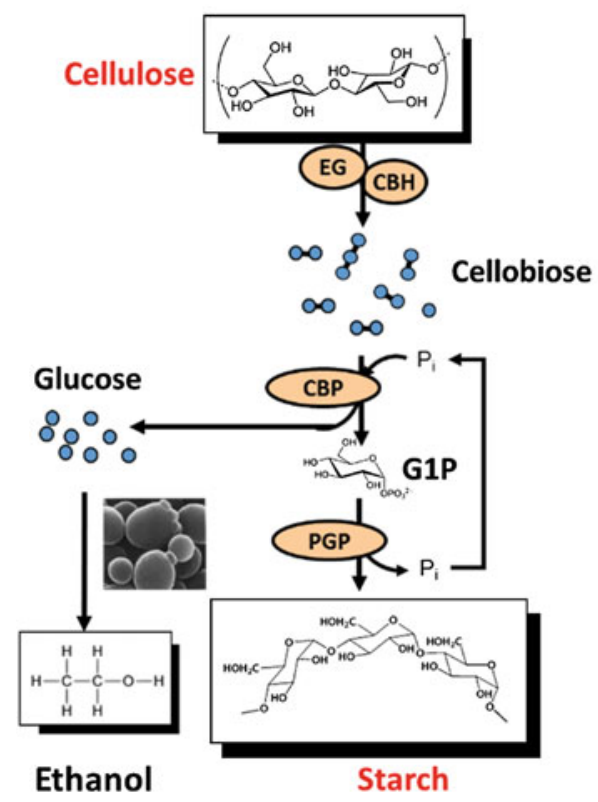

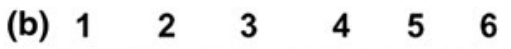

(c)
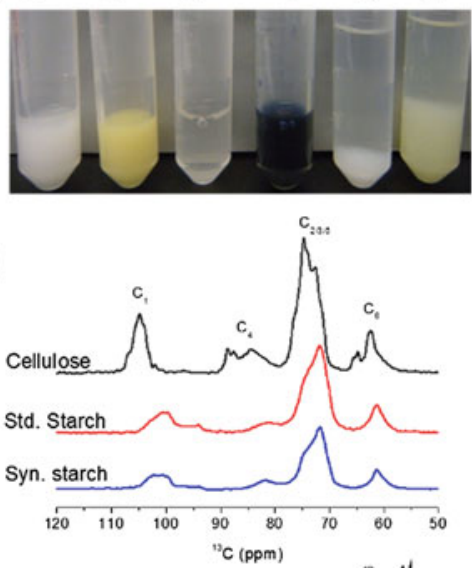

(d)

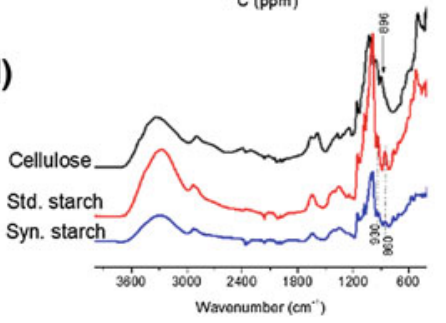

Fig. 6.2 The enzymatic transformation of converting cellulose to starch by endoglucanases (EGs), cellobiohydrolases (CBHs), cellobiose phosphorylase (CBP), and potato alpha-glucan phosphorylase (PGP), and the residual glucose was taken up by yeast to produce ethanol (a). Characterization of synthetic starch by iodine test (b), cross-polarization magic angle spinning (CP/M AS) ${ }^{13}$ C-NMR (c) and FTIR (d). Tube 1: cellulose-suspended solution; tube 2: cellulose solution plus iodine/potassium iodide; tube 3: water-soluble synthetic starch solution made from cellulose mediated by the four-enzyme cocktail; tube 4: synthetic starch solution plus iodine/potassium iodide; tube 5: precipitated starch by ethanol addition; and tube 6: precipitated starch when the mixture was supplemented with glucose oxidase [16]

This bioprocess called simultaneous enzymatic biotransformation and microbial fermentation can transform pretreated biomass to amylose, ethanol, and yeast as a single-cell protein in one bioreactor.

It is important to identify the right enzymes suitable for this ex vivo biotransformation. Enzymatic cellulose hydrolysis usually requires synergistic action of $\mathrm{EG}, \mathrm{CBH}$, and beta-glucosidase (BG) to yield glucose. But in our process, beta-glucosidase is not allowed because this enzyme hydrolyzes cellobiose to glucose, which cannot be added to starch chains. We tested the combinations of two EGs [family 5 Bacillus subtilis EG (BsCel5) and Trichoderma spp. EG II (TrCel5A)] and three CBHs family 7 Trichoderma spp. CBH (TrCel7A), family 9 
(a)

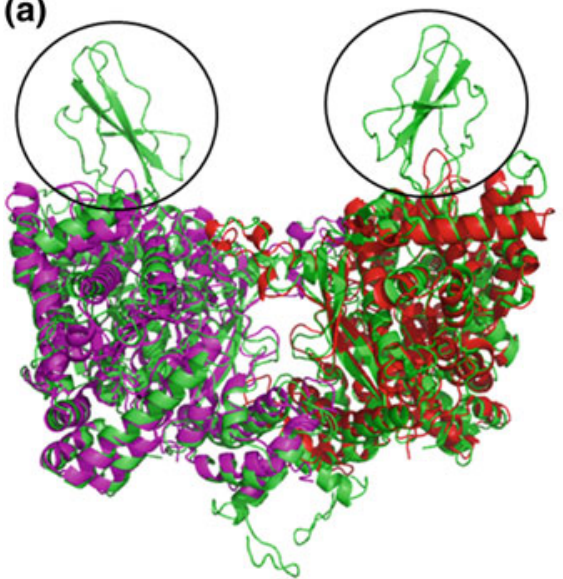

(b)

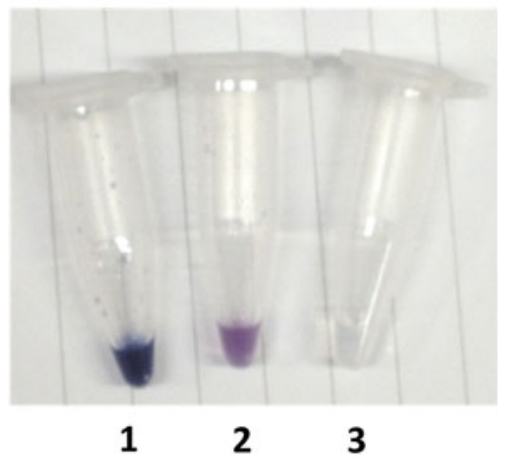

Fig. 6.3 Homology structure comparison between PGP (green) and Clostridium thermocellum alpha-glucan phosphorylase (purple and red), the circled regions represent cap structure of PGP (a) and photos of starch-synthesizing ability (b) based on cellobiose mediated by CBP and wild-type PGP (Tube 1), partially decapped PGP (Tube 2) or completely decapped PGP (Tube 3) [16] 
of cellulose), and the number-average degree of polymerization (DP) was $\sim 150$. The addition of glucose oxidase to remove glucose, a strong inhibitor of CBP, resulted in a yield increase to $30.0 \%$. And the formation of amylose was also validated by ${ }^{13} \mathrm{C}-\mathrm{NMR}$ and FTIR (Fig. 6.2c, d).

Alpha-glucan phosphorylase from $C$. thermocellum and $T$. maritima were tested for the negative production of amylose from cellulose. Comparison of the primary sequences of these three $\alpha \mathrm{GP}$ indicates that the residues involved in substrate binding and catalysis are fairly conserved. However, homology modeling of the structures of the three $\alpha$ GPs reveals that potato $\alpha \mathrm{GP}$ has a special cap consisting of residues from 478 to 561, which was absent in the other two bacterial enzymes (Fig. 6.3a). This cap structure can be observed in many plant aGPs, e.g., from sweet potato (Ipomoea batatas), spinach (Spinacia oleracea), rice (Oryza sativa), and wheat (Triticum aestivum) but as yet reported in bacteria. We hypothesized that the polypeptide cap on the catalytic site of PGP was responsible for driving low concentration G1P toward the synthesis of amylose. We designed two PGP deletion mutants - one had a part of the cap sequence removed and the other without the entire cap. In the buffer containing cellobiose and CBP, the partially "decapped" PGP (PGP-PDC) had decreased amylose synthesis ability compared to the wild-type enzyme (Fig. 6.3b, tube 2), whereas, the completely decapped PGP (PGP-CDC) lost the activity completely (Fig. 6.3b, tube 3). The kinetic parameters, $K_{\mathrm{m}}$ and $k_{\text {cat }}$ values ofPGP, PGP-PDC, PGP-CDC, $C$. thermocellum $\alpha \mathrm{GP}$ and T. maritima $\alpha \mathrm{GP}$ are compared in Table 6.1. The complete removal of the cap of PGP decreased the $k_{\mathrm{cat}} / K_{\mathrm{m}}$ values from 3.33 to $0.43 \mathrm{mM}^{-1} \mathrm{~s}^{-1}$ in the starch synthesis direction and from 0.55 to $0.06 \mathrm{mM}^{-1} \mathrm{~s}^{-1}$ in the starch degradation direction. Compared to the $C$. thermocellum $\alpha \mathrm{GP}$, PGP has a higher $k_{\mathrm{cat}} / K_{\mathrm{m}}$ value in the synthesis direction and a lower $k_{\mathrm{cat}} / K_{\mathrm{m}}$ in the degradation direction, suggesting that wild-type PGP has a preferred function for starch synthesis to degradation.

These enzymes were used to produce amylose from pretreated natural biomass, such as diluted acid-pretreated and cellulose solvent- and organic solvent-based lignocellulose fractionation (COSLIF)-pretreated corn stover [20]. In those reactions, nonutilized glucose units generated from the cellulase and CBP were assimilated by the baker's yeast; the baker's yeast can produce ethanol or other biochemical or single-cell proteins. Because typical baker's yeast cannot utilize cellobiose and G1P, adding yeast in this reaction system can increase the product yield by removing glucose which is the inhibitor of cellobiose phosphorylase [17, 18]. Under the tested conditions, the amylose yields were 23 and $2 \%$ for COLISF-pretreated corn stover and dilute acid pretreated corn stover, respectively. This data indicated that starch can be produced from pretreated natural lignocellulose. 


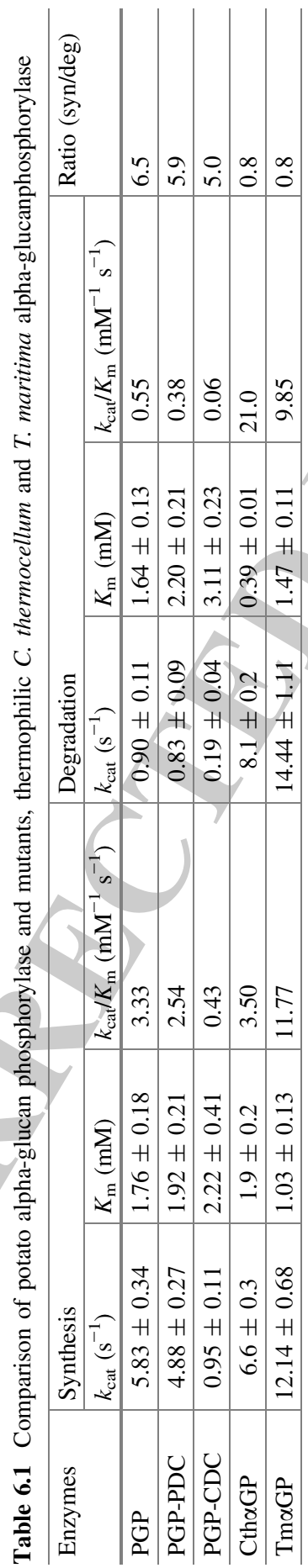




\subsection{Proposed Methods to Increase the Efficiency of Converting Cellulose to Starch}

The cost-effective transformation of non-food cellulose to starch could revolutionize agriculture and the fledgling bioeconomy, while maintaining biodiversity, minimizing agriculture's environmental footprint, and conserving fresh water [8]. This transformation would not only promote the cultivation of plants chosen for rapid growth rather than those optimized for starch-rich seed production, but it would also efficiently utilize marginal land for the production of the biomass required to meet the increasing needs of biofuels and renewable materials [21-23]. Therefore, increasing the efficiency of converting cellulose to starch could lead to the sustainable agricultural revolution.

\subsubsection{Increasing Cellulose Pretreatment Efficiency}

The goal of biomass pretreatment is to improve the enzymatic digestibility of pretreated lignocellulosic biomass. Many factors, such as substrate accessibility to hydrolytic enzymes, lignin content, cellulose degree of polymerization, particle size, and so on, are related to its recalcitrance [24, 25]. Among these factors, substrate accessibility is the most important substrate property impacting the efficiency of enzymatic cellulose hydrolysis [20]. Solvent-based biomass pretreatments can greatly increase cellulose accessibility compared to conventional biomass pretreatments, e.g., dilute acid, steam explosion and hot water [26]. Solvent-based lignocellulose pretreatments by using concentrated phosphoric acid and ionic liquids have the apparent advantages of: high glucan digestibility at low enzyme loading; fast hydrolysis rate; and potential revenues from separated coproducts (e.g., hemicellulose, lignin). In such case, an ideal solvent should be able to dissolve cellulose at modest temperature (i.e., low energy input and less sugar degradation) and those of wet cellulose so that no biomass drying step is required. In addition, the solvent should be highly recyclable nonvolatile or highly volatile for easy recycling; thermostable and chemostable for an unlimited number recycling; and nontoxic to the sequential steps of enzymatic hydrolysis and microbial fermentation. High cellulose dissolution capacity ( $>10 \mathrm{wt} \%$ cellulose/vol) and fast diffusion rate in solid lignocellulose composite are additional desirable properties of such a solvent system [26].

\subsubsection{Increasing PGP Thermostability}

Because PGP lose its activity quickly above $45^{\circ} \mathrm{C}$, the reaction is better be performed at $37{ }^{\circ} \mathrm{C}$ despite the other enzymes can work at about $50{ }^{\circ} \mathrm{C}$, resulting in 
low reaction rate of the whole process. High thermostable $\alpha \mathrm{GP}$ which favors starch synthesis is required to increase the efficiency of this ex vivo enzymatic pathway. Plant $\alpha$ GPs should have the best ability for starch synthesis compared to microbial homologs. However, few plant $\alpha \mathrm{GPs}$ can work at $>50^{\circ} \mathrm{C}$. In lieu of using naturally occurring enzymes, an option is to engineer current PGP to a thermostable one by protein engineering via directed evolution or rational design. Accordingly, a mutant library of PGP was generated by error-prone PCR, and the mutated plasmid library was transformed in Escherichia coli BL21 (DE3). Screening for the more stable PGP mutants can be conducted at $50{ }^{\circ} \mathrm{C}$ on agar plates containing $0.05 \%$ soluble starch had been described by Yanase et al. [27]. Blue spots stained by iodine solution on the filter indicated the presence of active PGP after heat treatment. Three mutations (F39L, N135S, and T706I) combined together enhanced the thermostability of PGP significantly without compromising activity, retaining almost all the activity after heat treatment at $60{ }^{\circ} \mathrm{C}$ for $2 \mathrm{~h}$ while wild-type enzyme was completely inactivated.

\subsubsection{Use of Commercial Cellulases}

In our previous work, we used a bacterial cellulase, $\mathrm{BsCel} 5$ endoglucanase that was expressed and purified from recombinant E. coli strain, and a purified Trichoderma cellobiohydrolase (TrCel7A). Bacterial cellulase is not as good as the secreted Trichoderma cellulase, because of its high production cost based on E. coli cell culture. Novozymes and Genecor (Dupont) areselling less costly (e.g., \$20/kg dry weight of cellulase) cellulase mixture products, like $\mathrm{CTec} 2$, HTec2, etc., that are highly efficient in converting amorphous cellulose to glucose. However, these commercial cellulases contain $\beta$-glucosidase activities that are designed to hydrolyze cellobiose to glucose. Hence, it is important to selectively remove $\beta$-glucosidase or produce $\beta$-glucosidase-free cellulase cocktail for meeting our special need here.

\subsubsection{Engineering of Yeast}

The yeast $S$ cerevisiae used in SEHF could be further improved by strain development. In general, yeast has been engineered to produce ethanol from cellulose directly by the expression of foreign cellulases including EG, CBH, and EG [2833]. These three enzymes could be assembled as an enzyme complex by the interaction between cohesin and dockerin through synthetic mini-scaffolding that is displayed on the yeast cell surface. Instead, we just need to replace BG with CBP and PGP enzymes. So four enzymes (EG, CBH, CBP, and PGP) and synthetic scaffolding can be expressed in yeast, and displayed on the yeast cell surface. 
A cellulose-enzyme-microorganism (CEM) complex is expected to enable more efficient cellulose hydrolysis, starch synthesis, and ethanol production [34]. However, before this is realized, many factors should be taken into account to improve the efficiency of this ex vivo system, e.g., cellulase selection, the number of cohesions and their order in scaffolding, linker length, and enzyme orientation.

\subsection{The Application of Synthetic Linear Amylose}

The only way to synthesize pure amylose is by means of phosphorylase-catalyzed enzymatic polymerization [35, 36] because natural amylose isolated from seeds always contains some small $\alpha-1,6$ branches. The length of synthetic linear amylose can be controlled by the concentration of primer oligosaccharides, G1P concentration, and reaction time. Synthetic amylose could have a variety of application, from low-value to high-value products (Fig. 6.4). (1) Top-quality synthetic amylose with a well-controlled degree of polymerization can be used as a chromatographic column matrix and drug capsule material in the pharmaceutical industry. (2) Amylose can be used to make biodegradable plastics, where starch-based plastics account for $50 \%$ of the bioplastic market [37]. High-quality linear amylose is suitable for producing clear, transparent, and flexible low-oxygen diffusion plastic sheets and films [38]. (3) Amylose is an important thickener, water binder, emulsion stabilizer, and gelling agent in the food industry. (4) Food-grade amylose can be blended with regular cereals and processed to high-amylose tailored foods for meeting special dietary needs [36, 39]. These lower glycemic load foods can improve human health and lower the risk of serious noninfectious diseases (e.g., diabetes and obesity) [40]. Amylose can be processed to form a resistant starch, which resists digestion and passes through to the large intestine, where it acts as a dietary fiber [41]. Slowly digestible and resistant starch has some healthy benefits, including the prevention and alleviation of metabolic diseases and the prevention of colon cancer [42]. (5) Medium-quality amylose can be used as a high-density hydrogen carrier for the enzymatic production of hydrogen, that could solve the challenges associated with hydrogen production, hydrogen storage, infrastructure, and safety concerns [13, 43, 44]. (6) Low-quality amylose mixed with yeast cells can be used as animal feed for nonruminant animals, such as pigs and chickens, where yeast cells are a protein source. (7) Amylose could be converted into other food nutrients. To increase amylose digestion efficiency as food/feed, the addition of the starch-branching enzyme converts linear amylose to branched amylopectin [45] (Fig. 6.4) that is more water soluble and easily digested than amylose.

The production of the polysaccharides amylose and amylopectin rather than glucose is essential as key food components because over-consumption of simple sugars (e.g., glucose and fructose) is strongly associated with noninfectious diseases, such as diabetes and obesity. It is why humans have to eat starch as a major calories source instead of drinking simple sugar solutions. Starch may be an 


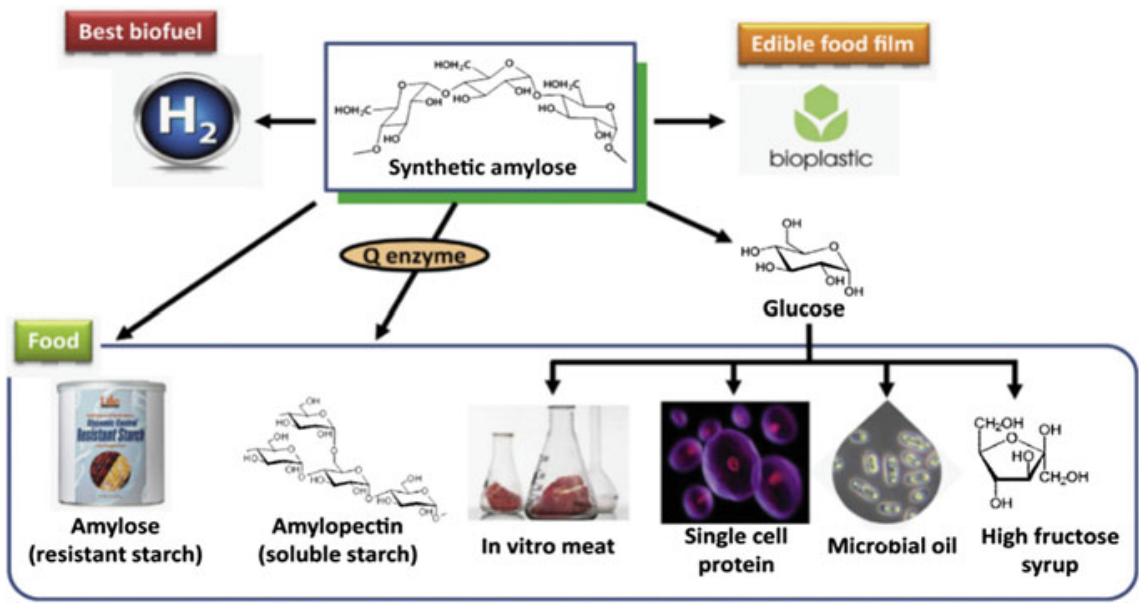

Fig. 6.4 The central role of synthetic amylose made from cellulose as new food sources (e.g., resistant starch, soluble amylopectin, in vitro meat, single-cell protein, microbialoil and high-fructose syrup), biodegradable plastic, and a hydrogen carrier. Reprinted from Ref. [6], Copyright 2015, with permission from Elsevier

important carbon source to produce other food nutrients, such as in vitro meat, single-cell proteins, and microbial oil. For example, slowly utilized starch is a better energy source for cell-free protein synthesis than glucose [46, 47].

\subsection{Conclusion}

To meet the growing needs of biofuels and renewable materials, as well as food and feed, we proposed an ex vivo enzymatic pathway along with microbial fermentation to produce edible starch from/cellulose and other value-added products. This method provides a potential alternative to solve the potential food crisis because cellulose resource is approximately 40 times the starch food produced by cultivated crops, whose production requires large amounts of arable land, water, and energy. Whereas, cellulosic crops like dedicated perennial bioenergy crops (e.g., switchgrass, bamboo, poplar) can grow on low-quality arable land with higher productivity, higher water utilization efficiency and less energy-related inputs compared to cultivated annual crops. So the cost-effective transformation of non-food cellulose to starch could lead to sustainable agriculture and potentially shape the bioeconomy, while maintaining biodiversity, minimizing agriculture's environmental footprint, and conserving fresh water. New biorefineries based on this technology could help address the food, biofuels, and environment trilemma; decrease the negative impacts of growing food and feed consumption on the environment; provide healthier food; and promote the bioeconomy. Because ex vivo synthetic 
biosystems cannot duplicate themselves, the large-scale implementation of cellulose-to-starch in new biorefineries would most likely not raise the questions about ethics, biosecurity, and biosafety that often confront in vivo synthetic biology projects.

\section{References}

1. Foley JA, Ramankutty N, Brauman KA, Cassidy ES, Gerber JS, Johnston M, Mueller ND, O'Connell C, Ray DK, West PC et al (2011) Solutions for a cultivated planet. Nature 478:337-342

2. Godfray HCJ, Beddington JR, Crute IR, Haddad L, Lawrence D, Muir JF, Pretty J, Robinson S, Thomas SM, Toulmin C (2010) Food security: the challenge of feeding 9 billion people. Science 327:812-818

3. The World Economic Forum Water Initiative (2011) Water security: the water-foodenergy-climate nexus. Island Press, Washington

4. Bruce TJ (2012) GM as a route for delivery of sustainable crop protection. J Exp Bot 63:537-541

5. Bagla P (2012) Negative report on GM crops shakes government's food agenda. Science $337: 789$

6. Chen H-G, Zhang YHP (2015) New biorefineries and sustainable agriculture: Increased food, biofuels, and ecosystem security. Renew Sustain Energy Rev 47:117-132

7. Varshney VK, Naithani S (2011) Chemical functionalization of cellulose derived from nonconventional sources. In: Kalia S, Kaith BS, Kaur I (eds) Cellulose fibers: bio- and nano-polymer composites. Springer, Berlin, pp 43-60

8. Somerville C, Youngs H, Taylor C, Davis SC, Long SP (2010) Feedstocks for lignocellulosic biofuels. Science 329:790-792

9. Wang Y, Huang W, Sathitsuksanoh N, Zhu Z, Zhang Y-HP (2011) Biohydrogenation from biomass sugar mediated by in vitro synthetic enzymatic pathways. Chem Biol 18:372-380

10. Xu Y, Masuko S, Takieddin M, Xu H, Liu R, Jing J, Mousa SA, Linhardt RJ, Liu J (2011) Chemoenzymatic synthesis of homogeneous ultralow molecular weight heparins. Science 334:498-501

11. Bujara M, Schümperli M, Pellaux R, Heinemann M, Panke S (2011) Optimization of a blueprint for in vitro glycolysis by metabolic real-time analysis. Nat Chem Biol 7:271-277

12. Swartz JR (2011) Transforming biochemical engineering with cell-free biology. AIChE J 58:5-13

13. Zhang Y-HP, Evans BR, Mielenz JR, Hopkins RC, Adams MWW (2007) High-yield hydrogen production from starch and water by a synthetic enzymatic pathway. PLoS ONE 2: e456

14. Guterl J-K, Garbe D, Carsten J, Steffler F, Sommer B, Reiße S, Philipp A, Haack M, Rühmann B, Kettling U et al (2012) Cell-free metabolic engineering-production of chemicals via minimized reaction cascades. ChemSusChem 5:2165-2172

15. Zhang Y-HP, Sun J-B, Zhong J-J (2010) Biofuel production by in vitro synthetic pathway transformation. Curr Opin Biotechnol 21:663-669

16. You C, Chen H, Myung S, Sathitsuksanoh N, Ma H, Zhang X-Z, Li J, Zhang Y-HP (2013) Enzymatic transformation of nonfood biomass to starch. Proc Natl Acad Sci USA 110:71827187

17. De Winter K, Cerdobbel A, Soetaert W, Desmet T (2011) Operational stability of immobilized sucrose phosphorylase: continuous production of $\alpha$-glucose-1-phosphate at elevated temperatures. Proc Biochem 46:2074-2078

18. Galazka JM, Tian C, Beeson WT, Martinez B, Glass NL, Cate JHD (2010) Cellodextrin transport in yeast for improved biofuel production. Science 330:84-86 
19. Zhang YHP, Cui J, Lynd LR, Kuang LR (2006) A transition from cellulose swelling to cellulose dissolution by o-phosphoric acid: evidence from enzymatic hydrolysis and supramolecular structure. Biomacromolecules 7:644-648

20. Rollin JA, Zhu Z, Sathisuksanoh N, Zhang Y-HP (2011) Increasing cellulose accessibility is more important than removing lignin: a comparison of cellulose solvent-based lignocellulose fractionation and soaking in aqueous ammonia. Biotechnol Bioeng 108:22-30

21. Sheppard AW, Gillespie I, Hirsch M, Begley C (2011) Biosecurity and sustainability within the growing global bioeconomy. Curr Opin Environ Sustain 3:4-10

22. French CE (2009) Synthetic biology and biomass conversion: a match made in heaven? J Roy Soc Interface 6:S547-S558

23. Casillas CE, Kammen DM (2010) The energy-poverty-climate nexus. Science 330:11811182

24. Himmel ME, Ding SY, Johnson DK, Adney WS, Nimlos MR, Brady JW, Foust TD (2007) Biomass recalcitrance: engineering plants and enzymes for biofuels production. Science 315:804-807

25. Chandra RP, Bura R, Mabee WE, Berlin A, Pan X, Saddler JN (2007) Substrate pretreatment: the key to effective enzymatic hydrolysis of lignocellulosics? Adv Biochem Eng Biotechnol 108:67-93

26. Sathitsuksanoh N, George A, Zhang YHP (2013) New lignocellulose pretreatments using cellulose solvents: a review. J Chem Technol Biotechnol 88:169-180

27. Yanase M, Takata H, Fujii K, Takaha T, Kuriki T (2005) Cumulative effect of amino acid replacements results in enhanced thermostability of potato type $\mathrm{L}$ alpha-glucan phosphorylase. Appl Environ Microbiol 71:5433-5439

28. Bae J, Kuroda K, Ueda M (2014) Proximity effect between cellulose-degrading enzymes displayed on the yeast cell surface. Appl Environ Microbiol

29. Tsai S, Oh J, Singh S, Chen R, Chen W (2009) Functional assembly of minicellulosomes on the Saccharomyces cerevisiae cell surface for cellulose hydrolysis and ethanol production. Appl Environ Microbiol 75:6087-6093

30. Wen F, Sun J, Zhao H (2010) Yeast surface display of trifunctional minicellulosomes for simultaneous saccharification and fermentation of cellulose to ethanol. Appl Environ Microbiol 76:1251-1260

31. Fujita Y, Ito J, Ueda M, Fukuda H, Kondo A (2004) Synergistic saccharification, and direct fermentation to ethanol, of amorphous cellulose by use of an engineered yeast strain codisplaying three types of cellulolytic enzyme. Appl Environ Microbiol 70:1207-1212

32. Nakatani Y, Yamada R, Ogino C, Kondo A (2013) Synergetic effect of yeast cell-surface expression of cellulase and expansin-like protein on direct ethanol production from cellulose. Microb Cell Fact 12:66

33. Yanase S, Yamada R, Kaneko S, Noda H, Hasunuma T, Tanaka T, Ogino C, Fukuda H, Kondo A (2010) Ethanol production from cellulosic materials using cellulase-expressing yeast. Biotechnol J 5:449-455

34. You C, Zhang XZ, Sathitsuksanoh N, Lynd LR, Zhang Y-HP (2012) Enhanced microbial utilization of recalcitrant cellulose by an ex vivo cellulosome-microbe complex. Appl Environ Microbiol 78:1437-1444

35. J-i Kadokawa (2011) Precision polysaccharide synthesis catalyzed by enzymes. Chem Rev 111:4308-4345

36. J-i Kadokawa (2012) Preparation and applications of amylose supramolecules by means of phosphorylase-catalyzed enzymatic polymerization. Polymers 4:116-133

37. van Soest JJG, Vliegenthart JFG (1997) Crystallinity in starch plastics: consequences for material properties. Trends Biotechnol 15:208-213

38. Frische R, Wollmann K, Gross-Lannert R, Schneider J, Best B (1994) Special amyloses and their use for producing biodegradable plastics

39. Maki KC, Pelkman CL, Finocchiaro ET, Kelley KM, Lawless AL, Schild AL, Rains TM (2012) Resistant starch from high-amylose maize increases insulin sensitivity in overweight and obese men. J Nutr 142:717-723 
40. Regina A, Bird A, Topping D, Bowden S, Freeman J, Barsby T, Kosar-Hashemi B, Li Z, Rahman S, Morell M (2006) High-amylose wheat generated by RNA interference improves indices of large-bowel health in rats. Proc Natl Acad Sci USA 103:3546-3551

41. Miao M, Jiang B, Cui SW, Zhang T, Jin Z (2015) Slowly digestible starch - a review. Crit Rev Food Sci Nutr 55:1642-1657

42. Gilbert R, Wu A, Sullivan M, Sumarriva G, Ersch N, Hasjim J (2013) Improving human health through understanding the complex structure of glucose polymers. Anal Bioanal Chem 405:8969-8980

43. Rollin JA, Martin del Campo J, Myung S, Sun F, You C, Bakovic A, Castro R, Chandrayan SK, Wu C-H, Adams MWW et al (2015) High-yield hydrogen production from biomass by in vitro metabolic engineering: mixed sugars coutilization and kinetic modeling. Proc Natl Acad Sci 112:4964-4969

44. Ye X, Wang Y, Hopkins RC, Adams MWW, Evans BR, Mielenz JR, Zhang Y-HP (2009) Spontaneous high-yield production of hydrogen from cellulosic materials and water catalyzed by enzyme cocktails. ChemSusChem 2:149-152

45. Peat S, Bourne EJ, Barker SA (1948) Enzymic conversion of amylose into amylopectin. Nature 161:127

46. Caschera F, Noireaux V (2014) Synthesis of $2.3 \mathrm{mg} / \mathrm{ml}$ of protein with an all Escherichia coli cell-free transcription-translation system. Biochimie 99:162-168

47. Wang Y, Zhang Y-HP (2009) Cell-free protein synthesis energized by slowly-metabolized maltodextrin. BMC Biotechnol 9:58 


\section{Author Query Form}

Book ID : 337251_1_En

Chapter No : 6

\section{黛 Springer}

the language of science

Please ensure you fill out your response to the queries raised below and return this form along with your corrections.

Dear Author,

During the process of typesetting your chapter, the following queries have arisen. Please check your typeset proof carefully against the queries listed below and mark the necessary changes either directly on the proof/online grid or in the 'Author's response' area provided below

\begin{tabular}{|l|l|r|}
\hline Query Refs. & Details Required & Author's Response \\
\hline AQ1 & $\begin{array}{l}\text { As Refs. [20] and [26] are the same, we have deleted the duplicate reference } \\
\text { and renumbered accordingly. Please check and confirm. }\end{array}$ & \\
AQ2 & \begin{tabular}{l} 
Please provide complete details for the Refs. [28, 38]. \\
\hline
\end{tabular}
\end{tabular}




\section{Please correct and return this set}

Please use the proof correction marks shown below for all alterations and corrections. If you wish to return your proof by fax you should ensure that all amendments are written clearly in dark ink and are made well within the page margins.

\begin{tabular}{|c|c|c|}
\hline Instruction to printer & Textual mark & Marginal mark \\
\hline Leave unchanged & ... under matter to remain & ( ) \\
\hline $\begin{array}{l}\text { Insert in text the matter } \\
\text { indicated in the margin }\end{array}$ & $h$ & $\begin{array}{l}\text { New matter followed by } \\
h \text { or } h \otimes\end{array}$ \\
\hline Delete & $\begin{array}{l}\text { I through single character, rule or underline } \\
\text { or }\end{array}$ & $\sigma$ or $\sigma / 2$ \\
\hline $\begin{array}{l}\text { Substitute character or } \\
\text { substitute part of one or } \\
\text { more word(s) }\end{array}$ & I through letter or & $\begin{array}{l}\text { new character / or } \\
\text { new characters / }\end{array}$ \\
\hline Change to italics & — under matter to be changed & $\leftarrow$ \\
\hline Change to capitals & $\equiv$ under matter to be changed & $\equiv$ \\
\hline Change to small capitals & $=$ under matter to be changed & $=$ \\
\hline Change to bold type & $\sim$ under matter to be changed & $\sim$ \\
\hline Change to bold italic & $\bar{\sim}$ under matter to be changed & 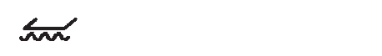 \\
\hline Change to lower case & Encircle matter to be changed & $\Rightarrow$ \\
\hline Change italic to upright type & (As above) & \\
\hline Change bold to non-bold type & (As above) & nor \\
\hline Insert 'superior' character & $\begin{array}{l}/ \text { through character or } \\
\alpha \text { where required }\end{array}$ & $\begin{array}{l}y^{\prime} \text { or } y \\
\text { under character } \\
\text { e.g. } y^{2} \text { or } y^{2}\end{array}$ \\
\hline Insert 'inferior' character & (As above) & $\begin{array}{l}\lambda \\
\text { over character } \\
\text { e.g. } \hat{\Sigma}\end{array}$ \\
\hline Insert full stop & (As above) & $\odot$ \\
\hline Insert comma & (As above) & , \\
\hline Insert single quotation marks & (As above) & $\begin{array}{l}\dot{y} \text { or } \dot{x} \text { and/or } \\
\dot{y} \text { or } \dot{y}\end{array}$ \\
\hline Insert double quotation marks & (As above) & $\begin{array}{l}\ddot{y} \text { or } \ddot{x} \text { and/or } \\
\ddot{y} \text { or } \ddot{x}\end{array}$ \\
\hline Insert hyphen & (As above) & 1 \\
\hline Start new paragraph & 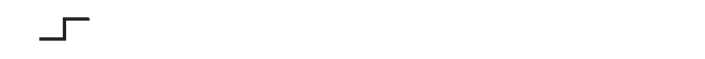 & 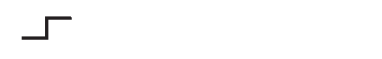 \\
\hline No new paragraph & $\omega$ & 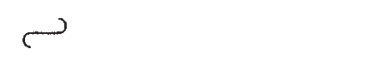 \\
\hline Transpose & $\sqcup$ & $\sqcup$ \\
\hline Close up & linking $\bigcirc$ characters & \\
\hline $\begin{array}{l}\text { Insert or substitute space } \\
\text { between characters or words }\end{array}$ & $\begin{array}{l}\text { I through character or } \\
\Lambda \text { where required }\end{array}$ & \\
\hline $\begin{array}{l}\text { Reduce space between } \\
\text { characters or words }\end{array}$ & $\begin{array}{l}\text { between characters or } \\
\text { words affected }\end{array}$ & $T$ \\
\hline
\end{tabular}

